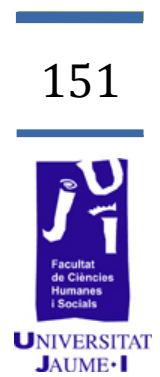

\title{
La renovación de la escultura figurativa en el cambio de siglo XIX-XX
}


A finales del siglo XIX París se convierte en la capital del mundo artístico y atrae a los nuevos artistas que buscaban crear un arte más acorde con las nuevas formas de vida de forma que supera los preceptos académicos a través de nuevos modelos plásticos.

En el ámbito de la escultura figurativa, destaca Auguste Rodin como gran renovador de una disciplina que había quedado atrapada en los cánones neoclásicos. A partir de su obra, la escultura emprende un nuevo camino y, más tarde, el escultor rosellonés Aristides Maillol retomará la revolución emprendida por Rodin dándole el último impulso para que el arte de las tres dimensiones abandone definitivamente el siglo XIX Y emprenda el nuevo siglo donde la dialéctica figuración-abstracción condicionará los lenguajes de representación.

En esta comunicación se dibujará un recorrido desde las premisas de la obra de Rodin que provocaron la ruptura con la escultura académica, hasta la interpretación que los nuevos escultores dieron a la obra de Maillol, con especial hincapié en los artistas catalanes que trajeron esta nueva figuración a nuestras fronteras.

Palabras clave: escultura, Rodin, Maillol, figuración, noucentisme, mediterraneismo.

\section{Introducción}

La siguiente comunicación presenta el resumen del punto de partida de la propuesta de la tesis doctoral de Adrián Arnau y este es el de establecer un linaje de escultores que a lo largo del siglo xx cambiarán el paradigma de la escultura en Cataluña. Examinando el estado de la escultura a finales del siglo XVIII y de su evolución a lo largo del XIX, a través de los grandes nombres de referencia en la escultura, llegaremos a entender el punto culminante que supuso la llegada del siglo Xx en la concepción de las teorías y la práctica escultórica.

Siempre dentro de los parámetros de la escultura figurativa, analizaremos cómo las propuestas de Auguste Rodin y Aristides Maillol supondrán una revolución, no únicamente en la estética, sino en toda la concepción de la escultura, de forma que abran el camino a la abstracción pero también a una nueva figuración.

\section{Objetivos}

Nuestro interés se centrará especialmente en cómo esta nueva figuración arraigará en Cataluña e impulsará a los escultores hacía una revisión del legado de la escultura clásica que transcienda las anteriores visiones del clasicismo para adentrar en la simplicidad y el equilibrio como 
vehículos que nos conducen a la esencia del culto a la belleza que profesaban los escultores de la Grecia clásica.

Así, el objetivo principal de la comunicación es evidenciar una tendencia en la evolución de la escultura de los dos últimos siglos que revolucionará el lenguaje escultórico e introducirá a esta disciplina, anclada en la tradición, en la modernidad que la pintura ya había iniciado con el Impresionismo.

El segundo objetivo es identificar las claves de cómo el desarrollo conceptual que supondrá la aparición de la obra de Rodin y Maillol cambiará la escultura en el territorio catalán.

\begin{abstract}
IV. Material y método
Para poder realizar un análisis como el que se pretende, ha sido necesario establecer una fuerte base bibliográfica que nos permita argumentar de manera sólida las características de la obra de cada uno de los escultores mencionados, así como de su influencia en la historia del arte.

Entre la bibliografía consultada se encuentran estudios sobre arte y escultura de los siglos XVII, XIX, y XX que nos han permitido establecer qué autores han sido los más influyentes en la renovación de la escultura. Partiendo de los resultados de la primera fase de la investigación se ha ampliado la búsqueda documental a monografías de los escultores más representativos.
\end{abstract}

\title{
V. Resultados
}

Después de analizar la bibliografía para establecer el marco de la investigación y el estado de la cuestión, se dibuja una tendencia en el desarrollo del lenguaje escultórico y en su pensamiento conceptual que, con matices, puede equipararse al desarrollo de la pintura.

El siglo XIX ve cómo el artista reclama su posición como intelectual, de forma que trasciende el carácter artesanal de algunas disciplinas. Este posicionamiento supondrá, en primer lugar, la devaluación de los aspectos técnicos de la escultura frente al tema, la composición, y otros componentes del oficio escultórico más relacionados con el intelecto que con el virtuosismo en la manufactura. Contemporáneamente, y gracias a los nuevos estudios sobre el mundo clásico resultantes de las excavaciones en el territorio de la antigua Magna Grecia, hace que la escultura se incline a una visión historicista de las formas clásicas.

La aparición de autores como Auguste Rodin y Aristides Maillol recuperará para la escultura una interpretación más viva del mundo clásico, que trascenderá la imitación y promulgará una vuelta a la escultura clásica que no se detenga en la estética, sino que escrutara los resortes íntimos de la concepción del arte griego. 


\section{Discusión y conclusiones}

Maillol es, junto con Rodin, el gran renovador de la escultura figurativa. Los dos franceses fueron clave para que la escultura decimonónica, de un academicismo decadente, reviviera para dar fruto a una nuevo ideal escultórico que podría dialogar con las propuestas artísticas más vanguardistas que traería el siglo $\mathrm{xx}$.

En los siglos precedentes, XVII y XVIII, los artistas, especialmente los escultores, habían reivindicado un papel que transcendiera la artesanía, rechazando que se les considerara meramente trabajadores manuales, y lucharon porque el público captara la verdadera dimensión de su obra. Esto hizo que se preponderara la inteligencia desplegada en el desarrollo de las obras más que la habilidad en la manufactura.

Las teorías de los filósofos alemanes tendrán en Francia, en el siglo XIX, una profunda influencia sobre la evolución de la noción de arte y sobre el comportamiento de los artistas, a través del movimiento literario del arte por el arte. El romanticismo alemán de fines del siglo XVIII y el romanticismo francés de comienzos del XIX van a hacer resurgir al artista del Renacimiento, ser de excepción o semidiós. (Gimpel, 1979: 105)

En la Academia, donde predominaba la estética y el lenguaje neoclásico, se insiste en una formación de talante humanístico, lo que conduce a la escultura a una recuperación de temas mitológicos como muestra de cultismo. Al entender la inteligencia como un aspecto fundamental en la creación, era necesario que el artista conociera y comprendiera el desarrollo histórico del arte, para poder crear a partir de la interpretación de los modelos heredados del pasado, especialmente del mundo clásico. Así, durante el siglo XIX, la escultura transita de la herencia ideológica y formal del siglo XVIII a los intereses historicistas del último tercio del siglo.

En este periodo, comienza a extenderse la idea de que el trabajo manual es indigno y que la verdadera obra de arte nace exclusivamente del intelecto. Los escultores, mayoritariamente, preferirán el trabajo del modelado en barro, y dejarán la tarea del paso a piedra o bronce en manos de los artesanos, de tal modo que el escultor, libre de las intensas jornadas y de la ardua tarea que supone el desbastado de la piedra o los procedimientos de fundición, puede dedicarse a la lectura de los clásicos, la contemplación o el disfrute de la música y la poesía. Los ejemplos del taller de Antonio Canova, donde se leen obras clásicas a la vez que se modela el barro, o Thorvaldsen, que se acompaña del piano del mismísimo Mendelssohn mientras trabaja.

Para este nuevo paradigma de la escultura la influencia de los escritos de Winckelmann sería decisiva, ya que popularizó que la escultura adquiriera en la sociedad un estatus que anteriormente no tenía. A través de su nueva concepción de la historia del arte, se desarrolló la estética neoclásica con una exaltación de los valores clasicistas y la mitología, lo que con el tiempo condujo a una escultura 
estereotipada y con un fuerte contenido moralista, que pretendía reaccionar contra la frivolidad del decorativismo del rococó.

Este cambio estuvo apoyado por los ideales de la ilustración, que surgían del racionalismo, $y$, en un creciente interés científico por la antigüedad clásica, provocó excavaciones arqueológicas y la formación de importantes colecciones públicas y privadas así como la publicación de estudios sobre el arte y la cultura grecorromana.

Bajo estas premisas, la escultura pondera por delante de todo la plasmación de un ideario que estilísticamente se basará en la repetición de los modelos clásicos, y donde los artistas infravalorarán los aspectos técnicos y dejarán de prestar atención a los materiales, de forma que crearán una homogeneidad de estilo que transcenderá fronteras, lo que como contrapartida supondrá la eliminación de la impronta local en beneficio de una estética más universal.

Hugh Honour parlà del neoclàssic com del primer estil internacional modern i indicà, encertadament, que el que perseguien els seus artífexs era la confecció d'un art de significat universal i validesa eterna.

Aquest estil, que coetàniament es descrivia com a estil «veritable» 0 "correcte» o, fins i tot, es qualificava com un segon risorgimento de les arts, va portar una sèrie de valors morals propis de la II-lustració als valors formals ja establerts a les Accadèmies. (Rodríguez Samaniego, 2013: 69)

A medida que se redundará en los estereotipos y la repetición devendrá copia de la estatuaria grecorromana sin aportar nuevos incentivos plásticos, esta corriente empezará a deteriorarse y perder fuerza, y llegará a finales del siglo xIx caduca y convaleciente a esperas de que la modernidad que comenzaba a vislumbrarse en la pintura llegara a las tres dimensiones (Alix, 2002: 22):

Las grandes transformaciones que había venido experimentando la pintura en el siglo XIX, desde los "plenairistas» hasta el Impresionismo, hacían aún más evidente el lamentable estado de la escultura y la urgente necesidad de renovación.

De entre los escultores de este primer tercio del siglo XIX podemos distinguir dos paradigmas que responden a dos generaciones sucesivas. Por un lado, se hayan escultores como los anteriormente citados Canova y Thorvaldsen, o Campeny en el territorio catalán, que recibieron sus enseñanzas en talleres tradicionales del siglo xVIII y que, por tanto, contaron con una base del conocimiento de los oficios escultóricos muy férrea, que, a pesar de que compartieran la concepción de la bajeza del trabajo material, conocen y dominan perfectamente los diferentes estados por los que una escultura debe pasar y son capaces de terminar sus esculturas una vez los obreros han realizado el vaciado y el sacado de puntos. En cambio, la generación que les seguirá estará formada por escultores que se iniciarán en una disciplina tan compleja, huérfanos de los conceptos formales y la sensibilidad hacia el oficio, con una formación 
notablemente más corta y precipitada y con los problemas que esta base insuficiente conllevará.

Las Academias son las encargadas de la formación de los jóvenes artistas y las que establecen concursos y becas de estudio en Madrid, Roma o París, además de imponer una rigidez basada en la imitación de la Antigüedad. Al concluir su pensionado, los más destacados se encaminan hacia puestos oficiales, como escultores de la corte o como cargos directivos en la Academia, cargos en todo caso que no permitían una experimentación formal, sino que más bien conducían a una perpetuación del modelo. La competitividad que se establece entre los artistas que optan a las condecoraciones y los méritos académicos $-y$, por tanto, a los cargos oficiales- a menudo va en detrimento del mismo quehacer creativo y se tienen más en cuenta las cualidades políticas y los contactos que la calidad de la obra.

Así el siglo XIX se iniciará con el movimiento neoclásico procedente del siglo anterior y con una generación de escultores que o bien no podía o bien no le interesaba -o ambas cosas- reformar una escultura autocomplaciente encaminada a moralizar y ensalzar la imagen del poder establecido, lo que en esa época supone una decadencia de la escultura religiosa que deja paso a una producción donde cobra importancia la escultura como elemento decorativo de la arquitectura. La realeza será su gran mecenas, que con la construcción de sus nuevos palacios o la reforma de los existentes hace necesario que se establezca la plaza de escultor de cámara (Alix, 2002: 20):

Pero aún es destacable otro aspecto que llegó a tener singular importancia en la degradación de la escultura: su tradicional utilización como monumento conmemorativo y como expresión de poder. A lo largo del siglo XIX, con la exaltación de las virtudes burguesas, su misión fundamental llegó a ser la de educar y ejemplificar, proporcionando modelos éticos y morales a las masas. De ahí la pertinaz continuidad de unos principios y normas estéticas inamovibles que convirtieron a la escultura en sinónimo absoluto de clasicismo. En todos los salones oficiales se exhibían cientos de esculturas en las que, invariablemente, se repetían los mismo modelos y formas...

La decadencia de la escultura a lo largo del siglo XIX deviene una situación insostenible. Por un lado, los escultores quieren proclamarse con todo derecho artistas del más alto nivel, por encima de cualquier connotación artesanal, pero, en cambio, la «intelectualización» de los escultores no trajo consigo un desarrollo artístico comparable al que se estaba produciendo en la pintura.

La escultura siempre ha avanzado de manera más lenta que la pintura, pero en este siglo, al menos en lo plástico, lo que se produjo fue una involución, ya que los modelos recuperados del pasado no aportaban nueva vida a la escultura, únicamente transmitían el gusto de la época por la recuperación del pasado, pero sin adentrarse realmente en la esencia más intima del arte clásico, de forma que resulta un clasicismo 
estéril que no podía revivir la arcadia, sino solamente contemplar cadáveres del pasado.

Evidentemente, en esta visión desoladora de la escultura se pueden divisar algunos brotes de escultura de una calidad sobresaliente. Nos referimos a escultores como los franceses François Rude (1784-1855) o Jean-Baptiste Carpeaux (1827-1875), o Damià Campeny (1771-1855), entre otros, en el territorio catalán (Wittkower, 2006: 626).

Hay en la primera mitad del siglo XIX, e incluso en la segunda, largos trechos bastante estériles en lo que toca al arte de la escultura, aunque no pretendo decir con ello que todo fuera malo. Cuando pensamos en la escultura del XIX en seguida se nos viene a la memoria una interminable serie de monumentos públicos más bien vulgares, procedentes principalmente de la segunda mitad del siglo. Son los Garibaldis, Vittorio Emanueles y compañía, como una plaga que hubiera caído sobre todas las ciudades europeas. No obstante, no faltaron los escultores de talento y las obras de gran calidad.

En las postrimerías del siglo, aparecen dos figuras clave que reconducirán esta tendencia decadente de la escultura y la renovarán desde los cimientos para que el siglo xx pueda contemplar un nuevo paradigma escultórico que enriquecerá este arte y lo situará en la vanguardia de las artes. Estamos hablando de Auguste Rodin y Aristides Maillol. Hasta la llegada de estos dos genios, la escultura continuó un revisionismo del pasado que contrastaba con la situación de la pintura, lanzada ya hacia la búsqueda de nuevos registros expresivos.

Se podría decir que la pintura, orientada a un mercado del arte más fluido y cosmopolita, miraba hacía el futuro, mientras que la escultura, supeditada a los grandes encargos de las altas esferas de la sociedad, quedaba encorsetada en una visión al pasado endogámica, que no se sumergía en las intimidades de la esencia clásica sino que se contentaba con la repetición de los modelos oficialmente considerados correctos (Selz, 1964: 37):

Si los pintores avanzaban lenta, pero irresistiblemente, hacia lo que unos veinte años más tarde sería el Impresionismo, los escultores continuaban con los ojos fijos en el "gran arte» del pasado. La noción de "gran arte» estaba ligada teóricamente al eterno prestigio de la estatuaria antigua. Pero lo que más directamente influenciaba a los escultores de 1850 era la obra de los que, medio siglo antes, habían sido también influenciados por la estatuaria grecorromana. El inmenso renombre de Antonio Canova y de Bertel Thorvaldsen no había sido aún superado.

La escultura que habría de venir en las postrimerías del siglo, no obstante, no se erigió sobre la negación de la herencia clásica como se podría pensar, sino que se reveló contra la lectura anodina que se había hecho durante las últimas décadas, pregonando una "verdadera» vuelta al clásico, no a su estética sino a su esencia, una revisión de los valores plásticos de la antigüedad, de su sensibilidad hacia la forma y de su culto a la belleza. 
Para el historiador Rudolf Wittkower, el cambio en el nuevo paradigma escultórico se establece a partir de dos corrientes divergentes. Ambas concebían que la necesaria regeneración de la escultura no pasaba por abandonar la tradición, pero evidenciaban claramente que la relación con el pasado no podía ser una limitación como hasta ese momento lo era la rigidez estilística neoclásica, sino que debía ser un escalera que aupara a los nuevos escalones a ver más allá.

Estas dos corriente las personifica Wittkower en los escultores Auguste Rodin y Adolf von Hildebrand. Resulta curiosa la elección del escultor alemán como referente del cambio escultórico, al ser un autor poco considerado y con una obra que no se encuentra entre las más valoradas por la crítica y la historia del arte. Sin embargo, en la propuesta de Wittkower la figura de Hildebrand es totalmente esencial, ya que tanto su obra escultórica como su legado teórico -especialmente su libro El problema de la forma en la obra de arte- ilustran a la perfección una de las dos vertientes hacia las que derivará la escultura finisecular.

La de Hildebrand es una escultura basada en la talla directa, como metodología y como filosofía. No se trata únicamente de la preferencia por el mármol como material, la elección de la técnica es en Hildebrand toda una declaración de intenciones, una visión profundamente teorizada de los procesos escultóricos. En su obra, no hay sitio para la improvisación, para la casualidad, ni para el azar, todo movimiento de su cincel responde a un razonado proceso de construcción de la forma. Su ideario fue reconocido ampliamente y su libro repetidamente reeditado y traducido a diferentes idiomas; su concepción de la forma como un problema casi abstracto nos conduce a una percepción de la anatomía que nos aleja del anecdotismo académico y acercaba la escultura figurativa a la geometría.

El hándicap de la propuesta de Hildebrand es que su labor intelectual profundizó en la esencia de la construcción formal basada en la geometría y el dibujo de los perfiles, pero le alejó de otra de las grandes características del arte griego, su devoción mística por la belleza.

Lo que no consigue Hildebrand con su teoría lo consigue Rodin con su sensibilidad. En la argumentación de Wittkower, Rodin es el polo opuesto a Hildebrand. El escultor francés basa su trabajo en el modelado y deja el proceso de talla a sus ayudantes; además, en general, prefiere la fundición en bronce.

La diferencia entre la talla directa y el modelado no responde únicamente a una predilección de uno y otro por un proceso de trabajo, el motivo es algo más profundo, es la respuesta a dos concepciones de la escultura bien diferenciadas. Si de Hildebrand destacábamos su profunda intelectualización de la forma y su capacidad de abstracción del proceso de creación, y poníamos en entredicho su falta de sensibilidad y su frialdad, en Rodin veremos claramente lo contrario.

El modelado de Rodin expresa el gesto y la intensidad de carácter, detalles del tratamiento formal que se pierden cuando la escultura se pasa a piedra, pero que se mantienen en su obra vaciada en bronce. 
Resulta evidente que la escultura de Rodin adquiere su mayor énfasis en el bronce, donde además de los rastros del gesto del escultor a menudo se sumaban los «defectos» producidos por el proceso de vaciado y que el escultor dejaba visibles para incrementar los recursos formales de su lenguaje. Esta concepción de la escultura, fresca, sin tabúes, surgida directamente de las entrañas, fascinó a los pintores de la época, especialmente a los impresionistas, y con ellos llego la admiración posterior del resto del mundo del arte. Las superficies vibrantes de la obra rodiniana entonaban con el puntillismo de la pintura impresionista, y con su intención de captar el momento. Rodin busca el movimiento, el gesto, la intención.

La escultura llega a finales del siglo XIX con la certeza de que el clasicismo de la Academia está caduco y necesita una renovación acorde a las nuevas tendencias exploradas por los pintores y con dos caminos para enfocar ese cambio. El mundo clásico seguirá siendo el punto de partida y el desnudo la piedra de toque, pero la concepción de la forma se liberará por fin de los cánones y explorará nuevos lenguajes, ya sea desde el intelecto o desde la pasión la escultura flirteará con la abstracción y dejará de pretender ser una copia para ser un lenguaje expresivo. Entre la disyuntiva de estos dos caminos aflorará la figura de Aristides Maillol, que será clave para integrar las visiones de Rodin y Hildebrand en una nueva figuración. Punto de equilibrio entre concepto y sentimiento, Maillol será el iniciador del camino por el que la escultura del siglo Xx avanzará hacia la abstracción en unos casos y hacia una figuración totalmente moderna en otros (Infiesta, 1975: 133).

Com tothom sap, o hauria de saber, és amb Maillol que comença l'escultura moderna: més ben dit, és amb la Mediterrània (1905) que l'escultura recupera la seva plena tridimensionalitat, s'allibera de tot llast superflu i s'encamina cap a una creixent abstracció.

La escultura de Maillol tuvo un efecto liberador para la escultura europea. A partir de su obra se podían replantear las ideas de clasicismo y arcaicismo sin miedo a caer en el academicismo; no obstante, la frontera entre el clasicismo académico y la modernidad de Maillol, es a menudo, una línea muy sutil que fácilmente se puede confundir, ya que el peso que en cierto sentido supone el legado del arte griego es, en ocasiones, una carga que cuesta de llevar para escultores e historiadores, que, al quedarse con una interpretación epidérmica de las formas clásicas, no llegan a empaparse del gran mensaje de la Grecia clásica: la exaltación de la belleza hasta el límite de la religiosidad (Salvadó Jassans, 1995: 66):

Comprenc que és difícil per a molts no veure mediterraneïtat en tota l'escultura neoclàssica centreeuropea, quan a primera vista s'assembla tant a la grega, però la realitat és una altra. Els neoclàssics només copiaven dels grecs les formes externes. Com si haguessin ressuscitat alguns cadàvers de l'antigor, però se'ls escapa l'essencial de l'esperit de Grècia que consisteix en l'alegria de viure i que els menà a fer de l'estimació a la bellesa una religió. 
Más allá de recuperar el sentido íntimo de la acción escultórica, el regreso a esa comunión entre vida y forma escultórica, la otra gran aportación de Maillol reside en la simplicidad formal y la eliminación de todo aquello que pueda entorpecer la contemplación de la forma, de todo detalle superfluo y toda anécdota ya sea narrativa o formal.

Frente a la fascinación que supuso para los impresionistas la obra de Rodin, había una obra palpitante, con superficies que reverberaban al presentar una superficie llena de irregularidades donde la luz se expandía en infinidad de matices, donde el gesto del escultor y las marcas de la técnica (en sus bronces era un recurso usual el dejar al descubierto las imperfecciones generadas por los moldes) constituían un paisaje rocoso, fascinante, siempre cambiante. Por el contrario, Maillol entiende que estos recursos son anecdóticos, que no aportan, sino que por el contrario distraen, en la contemplación de la forma. El maestro rosellonés propone una escultura limpia, donde nada nos detenga al recorrer la forma, donde la luz repose suavemente y los volúmenes se sucedan de manera orgánica sin accidentes.

Maillol, con su simplicidad, rescata la estética de la escultura griega arcaica. Una escultura con una representación simplificada de la anatomía humana, cercana a las formas geométricas, donde todas las formas tienden a la convexidad, como si estuvieran hinchadas, como si se expandieran de dentro hacia afuera, en las que se mantiene la dosis justa de rigor anatómico para conservar el contacto con las formas vivas, sin exceso de virtuosismo, pero intentando evitar la frialdad o la desconexión con la vida. Maillol pretende un justo equilibrio entre concepto e intuición, entre forma ideal y forma natural (Infiesta, 1974: 143).

\footnotetext{
Maillol era un hombre no dotado, como Cézanne. Llegaba al arte por conceptos, no por otra cosa. Maillol tenía un sentido eterno de la escultura, era como un griego. Tuvo la suerte de saber jugar a favor del tiempo en que vivía, y, entre sus aportaciones, cabe subrayar el que suprimiera ese sabor a grasa que era la cualidad que más se apreciaba en el siglo pasado.
}

Con Maillol llega una corriente de aire limpio, purificador, que hará que la escultura recupere su sentido primigenio, que la devolverá al origen mismo de la vida.

\section{Bibliografía}

AA. VV. (2007): Jassans: una vida dedicada a l'art de modelar, Universitat de Barcelona. Facultat de Belles Arts, Barcelona.

AbRIL, M. (1920): Enrique Casanovas. Tipografía Artística, Colección Estrella Volumen 1, Madrid.

AlIX, J. (2002): Un nuevo ideal figurativo. Escultura en España, 1900-1936. Fundación Cultural Mapfre Vida, Madrid.

BerguA, J. (1934): Historia de la escultura. Librería Bergua, Madrid. 
CAMPS Miró, T. (2002): «La configuración y consolidación del modelo figurativo en la escultura catalana del momento noucentista», Fundación Cultural Mapfre Vida, Madrid.

CAMPS MiRó, T. y S. PORTell (2015): Les cartes de l'escultor Enric Casanovas. Publicacions i Edicions de la Universitat de Barcelona, Barcelona.

CirLOT, J. E. (1956): La escultura del siglo XX. Omega, Barcelona.

ELíAS, F. (1926): L'escultura catalana moderna. Barcino, Barcelona.

ELSEN, A. (1967): Auguste Rodin. Lecturas sobre su vida y su obra. Editorial Diana, México D. F.

FLYNN, T. (2002): El cuerpo en la escultura. Akal, Madrid.

FontBonA, F. y A. E. Solà (1989): L'escultor Jassans. Àmbit, Barcelona.

García, J.M. (2004): Apel·les Fenosa. els quatre elements, rere les petjades

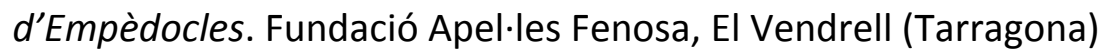

García Gutiérrez, P.F. Y J. Landa Bravo (1990): La escultura. Antiquaria, Madrid.

GIMPEL, J. (1979): Contra el arte y los artistas. Gedisa, Barcelona.

Gómez-Moreno, M. E. (1993): Pintura y escultura españolas del siglo XIX. Espasa-Calpe, Madrid.

GSELL, P. (1991): Auguste Rodin, conversaciones sobre el arte. Monte Ávila, Caracas.

Hamilton, G. H. (1980): Pintura y escultura en Europa: 1880-1940. Cátedra, Madrid.

Haskell, F., N. Penny y J. A. SuÁrez Hernández (1990): El gusto y el arte de la antigüedad: el atractivo de la escultura clásica, 1500-1900. Alianza, Madrid.

Hildebrand, A. Von (1989): El problema de la forma en la obra de arte. Visor, Madrid.

Hofmann, W. (1960): La Escultura del siglo xx. Seix Barral, Barcelona.

Hourtica, L. y M. L. Morales (1948): Historia de la escultura. Salvat, Barcelona.

INFIESTA Monterde, J. M. (1975): Un siglo de escultura catalana. Ediciones Aura, Barcelona.

Maderuelo, J. (2012): Caminos de la escultura contemporánea. Ediciones Universidad de Salamanca, Salamanca.

Marín-Medina, J. (1978): La Escultura española contemporánea, 18001978: historia y evaluación crítica. Edarcón, Madrid.

Martín González, J. J. (1964): Historia de la escultura. Editorial Gredos, Madrid. 
Martínez-Novillo, Á. y J. CAStro Arines (1987): Escultura figurativa, 19001950. Fundación Marcelino Botín, Santander.

MIRAlles, F. (2009): Fascinació per Grècia. L'art a Catalunya als segles XIX i $x x$. Museu d'Art de Girona, Girona.

Miralles, F. y J. SAlvadó Jassans (2003): Jassans: la pervivència de l'esperit clàssic. Diputació de Tarragona, Museu d’Art Modern, Tarragona.

Pons, A. y P. Parcerisas (1981): Hombres, tierras, Paisajes. Cataluña vista por sus artistas y escritores. Editorial H. M. B., Barcelona.

PRAT, J. L. (1981). Medio siglo de escultura: 1900-1945. Fundación Juan March, Madrid.

Racionero, L. (1985): El Mediterráneo y los bárbaros del Norte. Plaza, Esplugues de Llobregat.

Reyero, C. y M. Freixa (1995): Pintura y escultura en España: 1800-1910. Cátedra, Madrid.

Rodin, A., A. Le Normand-Romain, T. Dufrêne, y J. Alix, (2004): Rodin i la revolució de l'escultura: de Camille Claudel a Giacometti. Fundació «la Caixa», Barcelona.

Rodríguez SAMANIEgo, C. y J. Egea (2013): La imatge de l'heroi a l'escultura catalana (1800-1850). Grup de Recerca GRACMON, Universitat de Barcelona, Barcelona.

Salvadó Jassans, J. (1995): «Parlem d'escultura amb motiu de Julio Antonio", Revista de Catalunya, vol. 99, Septiembre, Barcelona.

SELZ, J. (1964): La escultura moderna, su origen y evolución. Editorial Eco, Barcelona.

SUBIRACHS, J. (1994): L'escultura del segle XIX a Catalunya: del romanticisme al realisme. Publicacions de l'Abadia de Montserrat, Barcelona.

Susanna, À., A. Papachristou y S. Walter (2015): Maillol i Grècia. Institut de Cultura de Barcelona, Barcelona.

TORMo y Monzó, E. (1903): La escultura antigua y moderna. Juan Gili, Barcelona.

WINCKELMANN, J. J. y L. UHLIG (1987): Reflexiones sobre la imitación del arte griego en la pintura y la escultura. Península, Barcelona.

WITTKOWER, R. (1980): La escultura: procesos y principios. Alianza forma, Barcelona. 